\title{
Awards Presented at the 47th Annual Meeting of the BEHAVIOR GENETICS ASSOCIATION
}

\author{
Thursday, July 1st, Oslo, Norway
}

(C) Springer Science+Business Media, LLC 2017

The Association's annual awards were presented at the Banquet. President-Elect Deborah Finkel served as the master of ceremonies.

The 40th Annual Thompson Award for the best oral presentation by an associate member was presented by Benjamin Neale to Emily Smith-Woolley for the presentation entitled "Differences in exam performance between school types mirrors genotype differences between them."

The 5th Annual Rowe Award for the best poster presentation by an associate member was presented by Eric Turkheimer to Laurence Tanguay-Garneau for the poster entitled "The etiology of stability and change in social withdrawal through childhood: a genetically informative study."

The 14th Annual Fuller and Scott Award for outstanding early career contributions to the field was presented by Brendan Zeitch to Karen Verviej.
The 17th Annual Fulker Award for the outstanding paper in Behavior Genetics during the past year was presented by John Hewitt, to Jenae Neiderhiser, and Valerie Knopik as editors of the 2016 special issue: "The importance of the prenatal environment in behavioral genetics". Behav. Genet. 46 (3).

The 40th annual Dobzhansky Award ${ }^{1}$ for outstanding lifetime contributions to the field of behavior genetics was presented to William Iaconno by Past-President Jaako Kaprio.

Respectfully Submitted,

Timothy Bates

Secretary, Behavior Genetics Association

Jaako Kaprio

Past President, Chair of the BGA Awards Committee

\footnotetext{
${ }^{1}$ Note added by Christina Hewitt (Managing Editor of the Behavior Genetics Journal) at the request of Associate Editor Lee Ehrman, to whom we are indebted for organizing the production of the Dobzhansky Award scroll: We would very much like to thank the new artist, Joseph A Thomasine, for producing such a beautiful scroll this year.
} 